\title{
PENERAPAN SMK3 DI INDUSTRI PEMBUATAN TAHU DI CIBATU GARUT DENGAN MENGGUNAKAN METODE 5 S
}

\author{
Paulus Sukapto ${ }^{1)}$, Sani Susanto ${ }^{2)}$, Hilmi I. Nursyam ${ }^{3)}$, Ulfa N. Ulumiah ${ }^{4)}$ \\ ${ }^{1,2}$ Teknik Industri UNPAR, ${ }^{3,4}$ Fakultas Pertanian, Universitas Garut. \\ 1paulus@unpar.ac.id
}

\begin{abstract}
Today, public knowledge, especially concerning the Occupational Safety and Health Management System (SMK3), will still be considered sorely lacking. In fact, if the understanding of SMK3 is good, the number of work accidents will be less, work productivity will be greater and finally the products produced will be higher in number with better quality. The purpose of the Community Service Program (Pengabdian kepada masyarakat) is to increase both understanding and knowledge of SMK3, and insight in Faculty of Agriculture, Garut University and industry players in Garut and its surroundings. In this program, site surveys as well as interviews before and after the seminar were conducted. The seminar material is an explanation of SMK3, that is to say the implementation of SMK3 during a pandemic in small and medium industries. After attending the seminar, the student in Faculty of Agriculture, Garut University and the industry players in Garut and its surroundings will have gained more in-depth knowledge of SMK3 and will try to implement it in the community properly and correctly. One way of implementing SMK3 is by way of 5S.
\end{abstract}

Keywords: SMK3, 5S, small and medium industries

\begin{abstract}
Abstrak
Dewasa ini, pengetahuan masyarakat khususnya tentang Sistem Manajemen Keselamatan dan Kesehatan kerja (SMK3) akan masih terbilang sangat kurang. Padahal, apabila pemahaman tentang SMK3 baik maka jumlah kecelakaan kerja semakin sedikit, produktivitas kerja semakin besar dan akhirnya produk yang dihasilkan jumlahnya semakin banyak dengan kualitas juga semakin baik. Tujuan dilaksanakan program PKM adalah menambah pemahaman, pengetahuan, dan wawasan di Fakultas Pertanian Universitas Garut dan pelaku industri di Garut dan sekitarnya tentang SMK3. Pada program ini dilakukan survei lokasi, wawancara sebelum dan sesudah seminar. Materi seminar adalah penjelasan mengenai SMK3, penerapan SMK3 dalam masa pandemi di industri kecil dan menengah. Setelah mengikuti seminar, mahasiswa Fakultas Pertanian Universitas Garut dan pelaku industri di Garut dan sekitarnya mengetahui secara lebih mendalam tentang SMK3 dan berusaha menerapkan dalam masyarakat dengan baik dan benar. Salah satu cara penerapan SMK3 dengan cara 5 S.
\end{abstract}

Kata Kunci: SMK3, 5 S, industri kecil dan menengah

\begin{tabular}{l|l|l} 
Submitted: $2021-06-22$ & Revised: $2021-07-24$ & Accepted: 2021-07-31
\end{tabular}

\section{Pendahuluan}

Saat ini industri kecil dan menengah merupakan aset penting yang mendukung perekonomian di Indonesia, karena jumlah industri kecil dan menengah cukup banyak dan mampu mendukung dalam menghasilkan devisa negara.

Pada industri kecil dan menengah, keselamatan dan kesehatan kerja menjadi masalah yang krusial karena sering kali diabaikan oleh pekerja maupun oleh pemiliknya. Padahal masalah keselamatan dan kesehatan kerja sudah dijelaskan dalam Undang-Undang Nomor 13 Tahun 2003 mengenai ketenaga-kerjaan pada Pasal 86 yang menyatakan bahwa pekerja memiliki hak perlindungan atas keselamatan dan kesehatan kerja. Salah satu penyebabnya adalah rendahnya tingkat pendidikan pekerja yang akan berpengaruh kepada tingkat awareness pekerja dan pemilik terhadap keselamatan dan kesehatan kerja. Pengetahuan yang kurang mengenai keselamatan dan 
kesehatan kerja menyebabkan pekerja menganggap bahwa kecelakaan yang biasa terjadi di tempat kerja sebagai hal yang tidak bisa dihindari dan diakibatkan oleh kelalaian pekerja.

Menurut Khanzode et al. (2012) menyatakan bahwa kecelakaan kerja dapat dihasilkan dari interaksi beberapa kejadian yang berurutan di dalam suatu sistem. Hal utama yang menyebabkan terjadinya kecelakaan adalah adanya potensi bahaya. Untuk itu, potensi bahaya perlu diidentifikasi dengan baik yang dapat muncul dalam suatu lantai produksi. Selain itu, Reason (2000) menjelaskan bahwa kecelakaan tidak hanya disebabkan oleh perilaku tidak selamat yang dilakukan manusia.

Kecelakaan kerja dapat terjadi pada pekerja dan juga alat yang digunakan karena tidak sesuai dengan standar keselamatan (O'Toole, 2002). Berbagai upaya telah dilakukan untuk mengurangi tingkat kecelakaan kerja yaitu solusi teknis, regulasi, dan faktor yang terkait dengan manusia (Törner et al., 2008). Akan tetapi, seperti yang disimpulkan oleh Nordlöf et al. (2015), Alli (2008), menyatakan bahwa sebaik apapun prosedur dan peraturan tersebut, aspek keselamatan dan kesehatan kerja ditentukan oleh nilai, sikap, persepsi, dan pola perilaku yang dianut dalam suatu organisasi atau yang sering disebut sebagai budaya keselamatan (safety culture).

Budaya keselamatan menjadi faktor penting dalam mewujudkan tempat kerja yang aman dengan tingkat kecelakaan rendah (Bergh et al., 2013). Sementara itu, untuk memberikan gambaran mengenai budaya keselamatan diperlukan iklim keselamatan (safety climate) mencerminkan persepsi bersama antara manajemen perusahaan dengan pekerja dalam melakukan setiap aktivitas di perusahaan. Budaya keselamatan hanya dapat berjalan dengan baik apabila terdapat persamaan persepsi diseluruh karyawan di dalam organisasi.

Seperti yang dikutip oleh Bergh et al. (2013), Clarke mengemukakan bahwa budaya keselamatan dan iklim keselamatan merupakan konsep yang saat ini banyak menarik perhatian berbagai kalangan di sektor industri. Iklim keselamatan dikembangkan oleh para peneliti untuk memaparkan kondisi serta persepsi pekerja terhadap keselamatan didalam organisasi (Clissold, 2004). Gambaran tentang iklim keselamatan dapat digunakan untuk menentukan baik atau tidaknya iklim keselamatan didalam organisasi dan dapat menunjukkan area mana saja yang perlu diperhatikan atau dikembangkan.

Keselamatan dan kesehatan kerja secara terus menerus mendapat perhatian yang besar karena berdampak pada aspek fisik dan finansial. Dalam beberapa tahun terakhir, banyak pihak yang memiliki perhatian khusus untuk mengatasi masalah keselamatan dan kesehatan kerja yang ada di industri kecil dan menengah. Salah satunya yang penting, ILO untuk sektor informal alas kaki di Indonesia adalah program pelatihan melalui buku petunjuk PATRIS (Pelatihan Aksi Bersama untuk Pelaku Sektor Informal) yang diterbitkan pada tahun 2003 oleh Kantor Perburuhan Internasional. Namun pada kenyataannya, program tersebut belum mampu diterapkan dengan baik karena memahami isi dari buku petunjuk tersebut serta pelaksanaan program yang tidak dikelola dengan baik, terutama pada sektor alas kaki informal di Cibaduyut.

Untuk itu, agar kesadaran masyarakat dan mahasiswa dalam keselamatan dan Kesehatan kerja maka perlu dilakukan suatu program pengenalan Sistem Manajemen Keselamatan dan Kesehatan Kerja agar dapat menjalankan aktivitas dengan baik dan benar sehingga mampu mewujudkan suasana kerja yang aman dan nyaman (Peraturan Menteri Tenaga Kerja No.5 Tahun 1996 Tentang Sistem Manajemen Keselamatan dan Kesehatan Kerja dan PP No. 50 Tahun 2012 tentang Penerapan Sistem Manajemen Keselamatan Dan Kesehatan Kerja).

Salah satu upaya untuk mewujudkan situasi kerja yang aman, nyaman dan kondusif di industri manufaktur adalah dengan menerapkan konsep 5S (Hudori, 2017). 5S merupakan metode penataan lingkungan kerja yang berasal dari Jepang. 5S ini merupakan singkatan dari Seiri, Seiton, Seiso, Seiketsu, dan Shitsuke yang secara bahasa Indonesia dapat diartikan sebagai Ringkas, Rapi, Resik, Rawat, dan Rajin. Pada dasarnya, 5S merupakan proses perubahan perilaku melalui perubahan tempat kerja dengan menerapkan penataan dan kebersihan tempat 
kerja (Diniaty, 2017). Penerapan 5S juga dapat membantu dalam mewujudkan tempat kerja dan suasana kerja yang kondusif, nyaman, aman, rapi, dan bersih yang secara tidak langsung akan membentuk budaya kerja, motivasi kerja dan meningkatkan produktivitas kerja (Meri, 2016).

\section{Metode}

Metode yang dilakukan dalam kegiatan ini adalah melalui beberapa tahap, yaitu Observasi langsung dan Penyuluhan/Pelatihan. Observasi langsung yaitu: Tim Abdimas langsung datang ke lokasi pengabdiaan untuk memperoleh data. Hal ini kami lakukan pada saat menjelang maupun saat kegiatan berlangsung. Observasi berguna untuk mengetahui kondisi dan kebutuhan yang diperlukan oleh mahasiswa Fakultas Pertanian Universitas Garut dan pelaku industri di Garut dan sekitarnya terhadap materi yang diperlukan dalam pelatihan penerapan SMK3. Observasi sangat penting untuk mewujudkan kesuksesan kegiatan pengabdiaan masyarakat itu sendiri. Dalam Penyuluhan/Pelatihan Tim Abdimas melakukan pelatihan pemahaman penerapan SMK3 kepada mahasiswa Fakultas Pertanian Universitas Garut dan pelaku industri di Garut dan sekitarnya. Selain itu juga memberikan tips-tips yang efektif supaya penerapan SMK3 bisa berjalan dengan baik.

\section{Hasil dan Pembahasan}

Metode pelaksanaan kegiatan berupa ceramah dan diskusi tentang SMK3. Diselengggarakan secara virtual pada 26 dan 27 April 2021. Pada tanggal 28 dan 29 April 2021, masing-masing kelompok membuat proyek penerapan SMK3 di masing-masing tempat kerja. Masing-masing kelompok terdiri atas rata-rata 5 orang. Hasil proyek dipresentasikan dan diskusikan oleh pihak narasumber pada tanggal 30 April 2021 masing-masing proyek. Alokasi waktu presentasi dan diskusi rata-rata 45 menit. Salah satu proyek yang pantas mendapatkan apresisasi adalah penerapan $5 \mathrm{~S}$ pada industri pembuatan tahu di Jl. Raya Cihuni Cibatu, Cimaragas, Pangatikan, Kabupaten Garut, Jawa Barat. Proses perbaikan diawali dengan pengamatan di lapangan dan selanjutnya pembuatan usulan perbaikan.

Tahap pertama adalah pengamatan di lapangan. Hasil pengamatan di pabrik pembuatan tahu menunjukkan bahwa adanya lingkungan kerja yang kurang bersih sehingga kemungkinan adanya kontaminasi dari tahu yang sedang diolah seperti Gambar 1. Keadaan ini menunjukkan ketidakteraturan dalam penataan lingkungan kerja. Selain itu di pabrik tahu ini juga ditemui kondisi lantai dan peralatan kerja yang masih kotor serta belum adanya pemberian label dan batas yang jelas pada penempatan peralatan kerja. Kondisi lingkungan kerja tersebut memerlukan beberapa upaya perbaikan melalui penerapan program " $5 S^{\text {". }}$

Berdasarkan hasil pengamatan di pabrik itu maka perlu merancang ulang tata letak fasilitas pabrik pembuatan tahu yang dapat meningkatkan produktivitas kerja. Menurut Sisca (2016), agar proses pengolahan tahu dapat berjalan dengan baik maka tahapan penerapan $5 \mathrm{~S}$ sebagai berikut.

1. Seiri. Metode Seiri dapat diterapkan pada stasiun perendaman dan penggilingan serta pada area gudang bahan jadi, karena pada kedua departemen ini terlihat jelas banyaknya peralatan pengolahan tahu seperti ember, tatakan tahu yang berserakan di lantai. Ember-ember ini terdiri dari ember yang berisi kedelai maupun yang berisi tahu yang sudah jadi dan ember yang kosong, sementara ember yang kosong ini tidak diperlukan dalam stasiun perendaman dan penggilingan serta pada gudang bahan jadi. Ember-ember yang kosong dan peralatan lainnya membuat lantai menjadi penuh sehingga tidak ada space bagi pekerja untuk melakukan proses perendaman dan penggilingan. Melihat keadaan tersebut maka diterapkanlah seiri yaitu dengan melakukan pemilahan terhadap ember - ember yang tidak diperlukan dan peralatan lainnya disimpan pada area diluar area gudang bahan jadi serta pada stasiun perendaman dan penggilingan. Dari hasil pemilahan, diperoleh space yang lebih luas sehingga pekerja lebih leluasa untuk melakukan pekerjaannya. Pekerjaan utama 
memindahkan kedelai yang sudah digiling ke stasiun perebusan menjadi lebih singkat karena tidak terhalang ember dan peralatan yang menghalanginya.

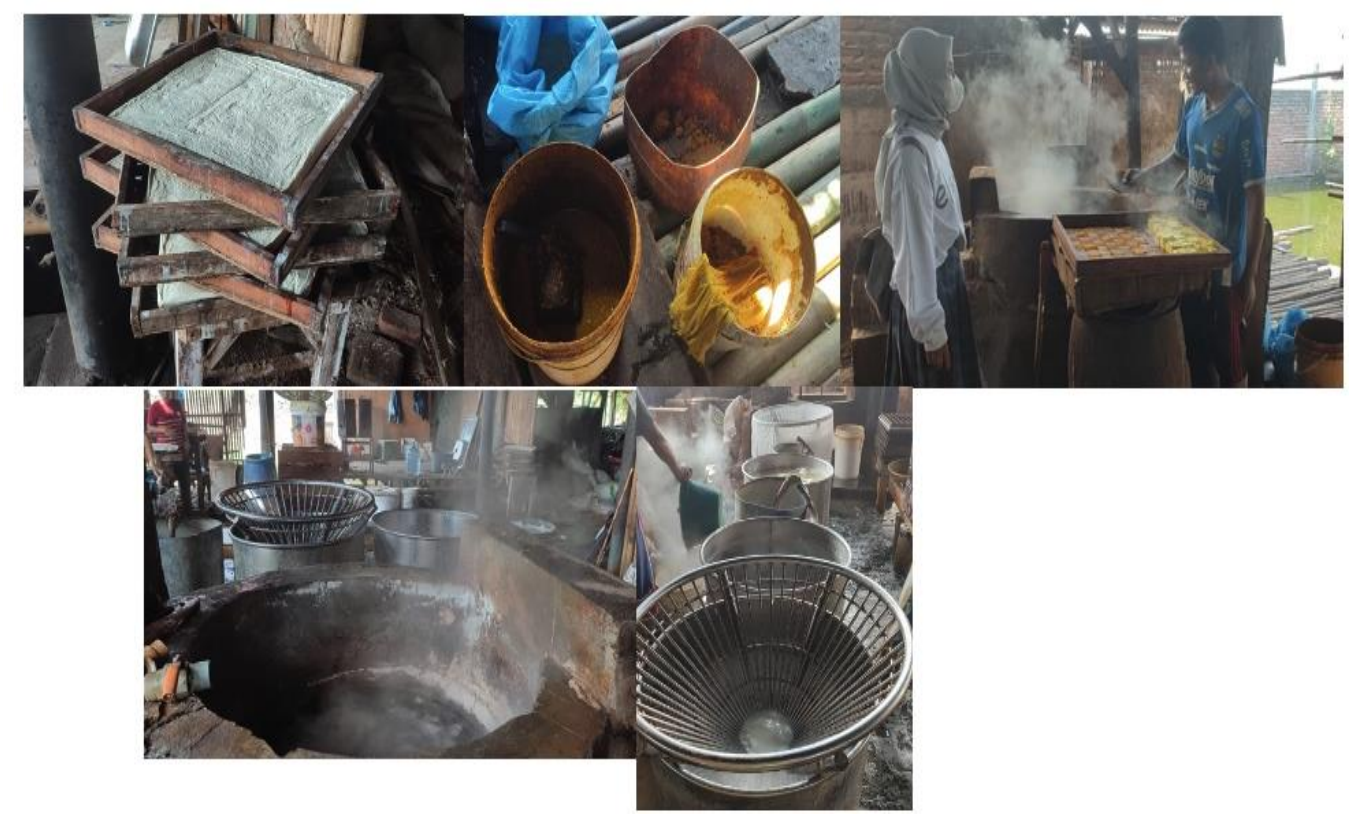

Gambar 1. Penempatan Peralatan Pengolahan Tahu yang Tidak Rapi dan Lingkungan Kerja Yang Kurang Bersih

2. Seiton. Pada tahap ini merupakan kelanjutan dari seiri yaitu proses penataan peralatan berupa ember dan alat lainnya. Sebagai contoh ember-ember yang ada pada stasiun perendaman dan penggilingan ditata pada area ember kosong tepatnya disamping gudang bahan jadi. Begitu juga dengan ember kosong yang bercampur pada gudang bahan jadi juga disusun pada area ember kosong. Selain penataan posisi ember, pada pabrik ini juga dilakukan penataan terhadap kain blacu yang digunakan untuk penyaringan ampas tahu dan juga penataan terhadap posisi alat press. Kain blacu . digantung sebaiknya diletakkan pada satu tempat saja sehingga akan memudahkan pekerja untuk mencari dan mengambilnya pada saat dibutuhkan. Sedangkan untuk alat lainya seperti press disusun pada stasiun pengepresan dan pemotongan. Alat press sebaiknya disusun diatas meja press dan potong sehingga pekerja lebih mudah mengambil dan menggunakannya.

3. Seiso. Pada tahap ini adalah proses pembersihan. Hal-hal yang menjadi perhatian utama dalam pembersihan adalah lantai produksi, mesin giling dan kuali perebusan dan pembibitan. Tujuan pembersihan lantai pabrik adalah membersihkan sampah-sampah berupa sampah plastik, kedelai yang terjatuh serta cairan sisa pencucian dan penggilingan kedelai. Lantai yang bersih akan mewujudkan tempat kerja yang aman, nyaman dan produktif. Sedangkan pembersihan peralatan akan menjaga agar alat tersebut tetap aman digunakan untuk pengolahan tahu.

4. Seiketsu. Proses ini adalah pemantapan terhadap metode $5 S$ yang telah diterapkan. Proses yang sudah berlangsung, yaitu dengan cara pembuatan label yang akan digunakan pada area bahan baku, area bahan jadi, tempat ember kosong, peralatan lainnya dan tempat kain blacu. Selain pembuatan label, pembuatan garis batas area kerja agar penyusunan peralatan kerja lebih tertata dengan baik. Pembuatan label dan garis batas area kerja bisa membuat karyawan 
mengetahui dimana penempatan peralatan yang digunakan dan juga mengetahui batas areanya. Dan yang lebih penting adalah proses ini dapat berlangsung secara terus menerus.

5. Shitsuke. Tahap ini merupakan bagian terakhir dari metode 5S. Proses ini lebih memfokuskan bagaimana cara untuk membiasakan diri terhadap penerapan keempat proses sebelumnya. Penerapan ini membutuhkan kesadaran secara sungguh-sungguh agar memiliki pola kerja yang sesuai metode $5 S$ untuk mewujudkan kondisi kerja yang aman, nyaman dan produktif. Penerapan 5S dapat berlangsung dengan baik diperlukan partisipasi seluruh level pekerja, baik dari level bawah sampai dengan level atas.

Untuk memperjelas penerapan tahapan $5 \mathrm{~S}$, pelaksanaan tugas di masing-masing stasiun atau departemen dapat dilihat pada Tabel 1 .

Tabel 1. Pelaksanaan 5S di masing-masing Stasiun Kerja.

\begin{tabular}{|c|c|c|}
\hline Metode 5S & Pelaksanaan & Stasiun/Departemen \\
\hline \multirow{2}{*}{$\begin{array}{l}\text { Seiri } \\
\text { (Pemilahan) }\end{array}$} & $\begin{array}{l}\text { Pemisahan peralatan dan ember yang } \\
\text { berisi kedelai dengan ember kosong }\end{array}$ & Perendaman dan Penggilingan \\
\hline & $\begin{array}{l}\text { Pemisahan peralatan dan ember yang } \\
\text { berisi tahu dengan ember kosong }\end{array}$ & Gudang bahan jadi \\
\hline \multirow{3}{*}{$\begin{array}{l}\text { Seiton } \\
\text { (Penataan) }\end{array}$} & $\begin{array}{l}\text { Peralatan dan ember yang kosong yang } \\
\text { telah dipisahkan dari ember-ember yang } \\
\text { berisi yang berada pada gudang bahan } \\
\text { jadi dan stasiun perendaman dan } \\
\text { penggilian di letakkan pada area } \\
\text { penempatan ember kosong }\end{array}$ & Area untuk alat dan ember kosong \\
\hline & $\begin{array}{l}\text { Kain blacu digantung pada satu tempat } \\
\text { saja yaitu pada area tempat kain blacu }\end{array}$ & Area Kain Blacu \\
\hline & $\begin{array}{l}\text { Peralatan alat untuk pengepresan } \\
\text { disusun pada meja pengepresan dan } \\
\text { pemotongan }\end{array}$ & Pengepresan dan Pemotongan \\
\hline \multirow{2}{*}{$\begin{array}{l}\text { Seiso } \\
\text { (Pembersihan) }\end{array}$} & Pembersihan Lantai Produksi & Lantai Produksi \\
\hline & Pembersihan Peralatan Kerja & Semua stasiun \\
\hline \multirow{3}{*}{$\begin{array}{l}\text { Seiketsu } \\
\text { (pemantapan) }\end{array}$} & Pembuatan garis batas-batas area kerja & $\begin{array}{l}\text { Perendaman dan Penggilingan, } \\
\text { Gudang Bahan Baku, Ember } \\
\text { Kosong }\end{array}$ \\
\hline & Pembuatan Jadual piket & - \\
\hline & Pembuatan label nama area & $\begin{array}{l}\text { Area gudang bahan baku dan } \\
\text { bahan jadi, area ember kosong dan } \\
\text { stasiun perendaman dan } \\
\text { penggilingan }\end{array}$ \\
\hline \multirow{2}{*}{$\begin{array}{l}\text { Shiketsu } \\
\text { (Pembiasaan) }\end{array}$} & Melakukan pengontrolan tiap hari & Semua stasiun \\
\hline & Upaya Pembiasaan diri & Semua stasiun \\
\hline
\end{tabular}




\section{Kesimpulan}

Hasil pelatihan 5S bagi mahasiswa Fakultas Pertanian Universitas Garut dan pelaku industri di Garut dan sekitarnya menunjukkan hasil yang baik, apabila ditinjau dari hasil akhir pembuatan proyek penerapan $5 \mathrm{~S}$ di berbagai industri di Garut dan sekitarnya. Dengan pelatihan ini mahasiswa Fakultas Pertanian Universitas Garut dan pelaku industri di Garut dan sekitarnya dapat lebih memahami konsep 5S, dengan materi-materi yang dilengkapi dengan foto-foto dan tambahan penjelasan contoh-contoh yang berhubungan dengan $5 \mathrm{~S}$, sehingga para semua peserta pelatihan mudah dalam menerapkan program $5 \mathrm{~S}$ di tempat kerjanya. Dalam menilai kemampuan mahasiswa mahasiswa Fakultas Pertanian Universitas Garut dan pelaku industri di Garut dan sekitarnya semua mampu menguasai materi yang diberikan.

\section{Daftar Pustaka}

Alli, B.O. (2008). Fundamental Principles Of Occupational Health and Safety (2nd Edition). Geneva : International Labour Organization.

Bergh, M., Shahriari, M., Kines, P. (2013). Occupational Safety Climate And Shift Work. AIDIC, 31, 403-408. doi: 10.3303/CET1331068

Clissold, G. (2004). Understanding Safety Performance Using Safety Climate And Psychological Climate. Melbourne: Monash University.

Diniaty, D., Hidayat, M. 2017. Analisis 5s Pada Stasiun Kerja Press dan Stasiun Kerja Boiler Di PT. Ekadura Indonesia. Seminar Nasional Teknologi Informasi, Komunikasi dan Industri (SNTIKI) 9 Fakultas Sains dan Teknologi, UIN Sultan Syarif Kasim Riau, hal 555-560.

Hudori, M. 2017. Penerapan Prinsip 5S (Seiri, Seiton, Seiso, Seiketsu, Shitsuke) di Gudang Zat Kimia Perusahaan Perkebunan Kelapa Sawit. Industrial Engineering Journal, Vol.6, No.2, pp. 45-52.

International Labor Organization. (2003). Meningkatkan Keselamatan, Kesehatan dan Lingkungan Kerja di Sektor Informal Alas Kaki (PATRIS). Jakarta, Kantor Perburuhan Internasional.

Khanzode, V. V., Maiti, J., \& Ray, P. K. (2012). Occupational Injury And Accident Research : A Comprehensive Review. Safety Science, 50, 1355-1367. doi: 10.1016/j.ssci2011.12.015

Meri, M., Wijaya, H. 2016. Analisa Penerapan5S di Warehouse Studi Kasus Warehouse Proyek Indarung VI PT. Semen Padang. Jurnal Teknologi Vo.6, No. 1, Juni 2016, Hal. 64-73.

Nordlöf, H., Wiitavaara, B., Winblad, U., Wijk, K., \& Westerling, R. (2015). Safety Culture And Reason For Risk-Taking At A Large Steel-Manufacturing Company: Invertigation The Worker Perspective. Safety Science, 73, 126-135. doi: 10.1016/j.ssci.2014.11.020

O'Toole, M. (2002). The Relationship Between Employees' Perceptions Of Safety And Organizational Culture. Journal Of Safety Research, 33, 231-243.

Peraturan Menteri Tenaga Kerja Nomor Per.05/MEN/1996 tentang Sistem Manajemen Keselamatan dan Kesehatan Kerja.

Peraturan Pemerintah Republik Indonesia Nomor 50 Tahun 2012 Tentang Penerapan Sistem Manajemen Keselamatan dan Kesehatan Kerja, Jakarta.

Reason, James. (2000). Human error: models and management. BMJ, 320, 768- 770. doi : $0.1136 / \mathrm{bmj} .320 .7237 .768$

Siska, M., Sari, L. F. 2016. Analisis Prinsip Kerja 5S dan Motivasi Karyawan di PT. Jasa Barutama Perkasa Pekanbaru Riau. Jurnal Sains, Teknologi dan Industri, Vol. 14, No. 1, pp.57-65 
Törner, M., Pousette, A., Kines, P., Mikkelsen, K. L., Lappalainen, J., Tharaldsen, J., \& Tómasson, K. (2008). A Nordic Questionnaire For Assessing Safety Climate (NOSACQ). Greece: Working on Safety Conference in Crete.

Undang-Undang No. 1 Tahun 1970 tentang Keselamatan Kerja. Indonesia. Undang-Undang Nomor 13 Tahun 2003 tentang Ketenagakerjaan. Keputusan Menteri Kesehatan RI No. 1405/MENKES/SK/XI/2002 tentang Persyaratan Kesehatan Lingkungan Kerja Perkantoran dan Industri. 